\title{
Helicobacter pylori in Vegetables and Salads: Genotyping and Antimicrobial Resistance Properties
}

\author{
Emad Yahaghi, ${ }^{1}$ Faham Khamesipour, ${ }^{2}$ Fatemeh Mashayekhi, ${ }^{3}$ \\ Farhad Safarpoor Dehkordi, ${ }^{2}$ Mohammad Hossein Sakhaei, ${ }^{4}$ \\ Mojtaba Masoudimanesh, ${ }^{4}$ and Maryam Khayyat Khameneie ${ }^{5}$ \\ ${ }^{1}$ Baqiyatallah University of Medical Sciences, Tehran, Iran \\ ${ }^{2}$ Young Researchers and Elites Club, Islamic Azad University, Shahrekord Branch, P.O. Box 166, Shahrekord, Iran \\ ${ }^{3}$ Intensive and Critical Care Nursing, Jiroft University of Medical Sciences, Jiroft, Iran \\ ${ }^{4}$ Scientific Association of Veterinary Office, College of Veterinary Medicine, Islamic Azad University, Shahrekord Branch, \\ P.O. Box 166, Shahrekord, Iran \\ ${ }^{5}$ Department of Gynecology, Imam Reza Hospital, AJA University of Medical Sciences, Tehran, Iran
}

Correspondence should be addressed to Maryam Khayyat Khameneie; dr.khameneie@yahoo.com

Received 3 February 2014; Revised 18 May 2014; Accepted 9 June 2014; Published 12 August 2014

Academic Editor: Gundlapally S. Reddy

Copyright (C) 2014 Emad Yahaghi et al. This is an open access article distributed under the Creative Commons Attribution License, which permits unrestricted use, distribution, and reproduction in any medium, provided the original work is properly cited.

From a clinical and epidemiological perspective, it is important to know which genotypes and antibiotic resistance patterns are present in $H$. pylori strains isolated from salads and vegetables. Therefore, the present investigation was carried out to find this purpose. Three hundred eighty washed and unwashed vegetable samples and fifty commercial and traditional salad samples were collected from Isfahan, Iran. Samples were cultured and those found positive for $H$. pylori were analyzed using PCR. Antimicrobial susceptibility testing was performed using disk diffusion method. Seven out of 50 (14\%) salad and 52 out of 380 (13.68\%) vegetable samples harbored $H$. pylori. In addition, leek, lettuce, and cabbage were the most commonly contaminated samples (30\%). The most prevalent virulence genes were oipA (86.44\%) and cagA (57.625). VacA sla (37.28\%) and iceAl (47.45\%) were the most prevalent genotypes. Forty different genotypic combinations were recognized. S1a/cagA+/iceA1/oipA+ (33.89\%), sla/cagA+/iceA2/oipA (30.50\%), and mla/cagA+/iceA1/oipA+ $(28.81 \%)$ were the most prevalent combined genotypes. Bacterial strains had the highest levels of resistance against metronidazole (77.96\%), amoxicillin (67.79\%), and ampicillin (61.01\%). High similarity in the genotyping pattern of $H$. pylori among vegetable and salad samples and human specimens suggests that vegetable and salads may be the sources of the bacteria.

\section{Introduction}

Vegetables are raised as complete foods. Their high values for minerals and vitamins are undeniable and, in a day, millions of people use the vegetables and salads in their main diet. Therefore, hygienic quality of vegetables and salad has a high importance in public health but sometimes it will be changed and several infections and illnesses will occur. Vegetables are in close contact with soil, animal manure, and even human stool. They are usually irrigated with polluted water. Previous studies showed that soil [1], water [2], animal manure $[3,4]$, and human stool $[5,6]$ are the main resources for Helicobacter pylori ( $H$. pylori). Therefore, vegetables can easily be contaminated with $H$. pylori. In addition, their crosscontamination in processing stages is irrefutable.

H. pylori is a gram-negative, spiral-shaped bacterium. Its main reservoir is human, particularly the human stomach. It colonizes most of the population, making it one of the most controversial bacteria in the world. $H$. pylori causes peptic ulcer, duodenal ulcer, gastritis, lymphoma, and gastric cancer [7]. According to the reports, the main routes of infection have not been clarified yet $[8,9]$. However, it is likely that $H$. pylori infection occurs during childhood or adolescence in both developing and developed countries $[8,9]$ and its transmission occurs by person to person, either by fecal-oral or oral-oral routes [1]. Nearly $50 \%$ of the world population is 
estimated to be infected with $H$. pylori [10]. The prevalence of this bacterium among Iranian people is $60-90 \%$, indicating that Iran is a high risk region for $H$. pylori infection [11].

Some of the most important virulence factors such as vacuolating cytotoxin $\mathrm{A}(\operatorname{vac} A)$, cytotoxin associated gene (cag), induced by contact with the epithelium antigen (iceA), outer inflammatory protein (oipA), and urease (ureC) play a major role in pathogenicity of $H$. pylori infection [12]. These genes are usually induced by adhesion to and invasion of the gastric epithelial cells [13-15]. Genotyping using these wellknown virulence marker genes is considered as one of the best approaches for study of correlations between $H$. pylori isolates from different samples $[16,17]$. The vacA gene has a mosaic structure comprising allelic variations in the signal $(s)$ and mid region $(m)$, each having two different alleles $(\mathrm{s} 1 / \mathrm{s} 2, \mathrm{~m} 1 / \mathrm{m} 2)$ with different biological activities. Several subregions including sla, slb, and slc and mla and mlb have been identified in $\mathrm{s} 1$ and $\mathrm{ml}$ regions, respectively [18]. Strains carrying the slm1 mosaic combination of the gene $v a c A$ exhibit higher levels of cytotoxic activity than slm2 strains, while $\mathrm{s} 2 \mathrm{~m} 2$ strains do not secrete the vacuolating cytotoxin [18]. The iceA gene has two main allelic variants, ice $A 1$ and ice $A 2$, but their functions are not yet clear. The cag pathogenicity island (PAI) has been shown to be involved in inducing ulceration, inflammation, and carcinogenesis [19]. The $\operatorname{cag} A$ was one of the most common genes in severe cases of peptic ulcer [20]. The oipA gene of the $H$. pylori plays an important role in successful colonization of mucosa [21, 22]. The oipA gene has the ability to induce interleukin (IL-8) from gastric epithelial cells, as cagA and its status have been linked to the discrimination of duodenal ulcer and gastritis $[21,22]$. Bacterial urease neutralizes the gastric $\mathrm{pH}$, enabling the colonization of gastric epithelial cells by the bacteria and their motility in the mucus layer $[21,22]$.

Treatment of diseases caused by $H$. pylori often requires antimicrobial therapy; however, antibiotic-resistant strains of bacteria cause more severe diseases for longer periods of time than their antibiotic-susceptible counterparts. Several studies have shown that antibiotic resistance in $H$. pylori has increased over time $[23,24]$.

Data on the distribution of genotypes and antibiotic resistance pattern of $H$. pylori strains isolated from vegetable and salad samples are scarce. Therefore, the aim of the present study was genotyping of $H$. pylori strains isolated from vegetable and salad samples and investigating their susceptibility to 13 commonly used antibiotics, as well as investigating seasonal variation in the prevalence of $H$. pylori.

\section{Materials and Methods}

2.1. Sample Collection and H. pylori Identification. A total of 380 washed and unwashed vegetable samples including leek $(n=20)$, radish $(n=20)$, basil $(n=20)$, parsley $(n=20)$, spinach $(n=20)$, lettuce $(n=20)$, cabbage $(n=20)$, carrot $(n=20)$, scallion $(n=20)$, chive $(n=20)$, fenugreek $(n=20)$, coriander $(n=20)$, pepper $(n=20)$, turnip $(n=20)$, beet $(n=20)$, garlic $(n=20)$, maize $(n=20)$, broccoli $(n=20)$, and cucumber $(n=20)$ and 50 commercial and traditional salad samples were collected from supermarkets and groceries of various parts of Isfahan Province, Iran (Table 2). Samples were collected over a year. Washed vegetables were processed using the high pressure water. All samples were immediately transferred to the Microbiology and Infectious Diseases Research Center of the Islamic Azad University, Shahrekord Branch, at $4^{\circ} \mathrm{C}$. Twentyfive milliliters of each homogenized sample was added to $225 \mathrm{~mL}$ of Wilkins-Chalgren anaerobe broth (Oxoid, UK) supplemented with $5 \%$ of horse serum and colistin methanesulfonate $(30 \mathrm{mg} / \mathrm{L})$, cycloheximide $(100 \mathrm{mg} / \mathrm{L})$, nalidixic acid $(30 \mathrm{mg} / \mathrm{L})$, trimethoprim $(30 \mathrm{mg} / \mathrm{L})$, vancomycin $(10 \mathrm{mg} / \mathrm{L})$ and colistin methanesulfonate $(30 \mathrm{mg} / \mathrm{L})$, cycloheximide $(100 \mathrm{mg} / \mathrm{L})$, nalidixic acid $(30 \mathrm{mg} / \mathrm{L})$, trimethoprim $(30 \mathrm{mg} / \mathrm{L})$, and vancomycin $(10 \mathrm{mg} / \mathrm{L})$ and incubated for 7 days at $37^{\circ} \mathrm{C}$ with shaking under microaerophilic conditions. Then, $0.1 \mathrm{~mL}$ of the enrichment selective broth was plated onto Wilkins-Chalgren anaerobe agar supplemented with $5 \%$ of defibrinated horse blood and colistin methanesulfonate $(30 \mathrm{mg} / \mathrm{L})$, cycloheximide $(100 \mathrm{mg} / \mathrm{L})$, nalidixic acid (30 mg/L), trimethoprim $(30 \mathrm{mg} / \mathrm{L})$, and vancomycin $(10 \mathrm{mg} / \mathrm{L})$ and incubated for 7 days at $37^{\circ} \mathrm{C}$ under microaerophilic conditions. For comparison, a reference strain of $H$. pylori (ATCC 43504) was employed.

2.2. Antimicrobial Susceptibility Testing. Pure cultures of $H$. pylori isolates were used for antibiotic susceptibility test. One strain from each $H$. pylori-positive sample was selected for susceptibility tests. Antimicrobial susceptibility testing was performed by the Kirby-Bauer disc diffusion method using Mueller-Hinton agar (HiMedia Laboratories, Mumbai, India) supplemented with 5\% defibrinated sheep blood and 7\% fetal calf serum, according to the Clinical Laboratory Standards Institute [25]. The antimicrobial resistance of $H$. pylori was measured against the widely used antibiotics in cases of $H$. pylori gastric ulcer. The following antimicrobial impregnated disks (HiMedia Laboratories, Mumbai, India) were used: metronidazole $(5 \mu \mathrm{g})$, ampicillin $(10 \mathrm{u} /)$, clarithromycin $(2 \mu \mathrm{g})$, erythromycin $(5 \mu \mathrm{g})$, tetracycline $(30 \mu \mathrm{g})$, amoxicillin $(10 \mu \mathrm{g})$, streptomycin $(10 \mu \mathrm{g})$, levofloxacin $(5 \mu \mathrm{g})$, rifampin $(30 \mu \mathrm{g})$, trimethoprim $(25 \mu \mathrm{g})$, cefsulodin $(30 \mu \mathrm{g})$, spiramycin $(100 \mu \mathrm{g})$, and furazolidone $(1 \mu \mathrm{g})$. After incubation at $37^{\circ} \mathrm{C}$ for $48 \mathrm{~h}$ in a microaerophilic atmosphere, the susceptibility of the H. pylori to each antimicrobial agent was measured and the results were interpreted in accordance with interpretive criteria provided by CLSI (2012) [26]. The H. pylori ATCC 43504 was used as control organisms in antimicrobial susceptibility determination.

2.3. Detection of Helicobacter pylori UreB Gene Using Polymerase Chain Reaction (PCR). Suspected colonies were identified as $H$. pylori based on the PCR technique. Genomic DNA was extracted from the colonies with typical characters of $H$. pylori using a DNA isolation kit for cells and tissues (Roche Applied Science, Germany, 11814770001) according to the manufacturer's instructions. Set of novel primers for $u r e B$ gene of the $H$. pylori was designed by the authors. Recorded sequences of the ureB gene of the 
TABLE 1: Oligonucleotide primers used for genotyping of Helicobacter pylori isolated from vegetables and salads in Iran.

\begin{tabular}{|c|c|c|}
\hline Genes names & Primer sequence $\left(5^{\prime}-3^{\prime}\right)$ & Size of product (bp) \\
\hline ureC & $\begin{array}{c}\mathrm{F}^{*}: \text { GCTTACTTTCTAACACTAACGCGC } \\
\mathrm{R}^{* *}: \text { GGATAAGCTTTTAGGGGTGTTAGGGG }\end{array}$ & 296 \\
\hline vacA sla & $\begin{array}{l}\text { F: CTCTCGCTTTAGTAGGAGC } \\
\text { R: CTGCTTGAATGCGCCAAAC }\end{array}$ & 213 \\
\hline$v a c A s 1 b$ & $\begin{array}{l}\text { F: AGCGCCATACCGCAAGAG } \\
\text { R: CTGCTTGAATGCGCCAAAC }\end{array}$ & 187 \\
\hline$v a c A s l c$ & $\begin{array}{l}\text { F: CTCTCGCTTTAGTGGGGYT } \\
\text { R: CTGCTTGAATGCGCCAAAC }\end{array}$ & 213 \\
\hline$v a c A s 2$ & $\begin{array}{l}\text { F: GCTAACACGCCAAATGATCC } \\
\text { R: CTGCTTGAATGCGCCAAAC }\end{array}$ & 199 \\
\hline $\operatorname{vac} A m 1 A$ & $\begin{array}{l}\text { F: GGTCAAAATGCGGTCATGG } \\
\text { R: CCATTGGTACCTGTAGAAAC }\end{array}$ & 290 \\
\hline$v a c A m 1 B$ & $\begin{array}{c}\text { F: GGCCCCAATGCAGTCATGGA } \\
\text { R: GCTGTTAGTGCCTAAAGAAGCAT }\end{array}$ & 291 \\
\hline$v a c A m 2$ & $\begin{array}{l}\text { F: GGAGCCCCAGGAAACATTG } \\
\text { R: CATAACTAGCGCCTTGCA }\end{array}$ & 352 \\
\hline $\operatorname{cag} A$ & $\begin{array}{l}\text { F: GATAACAGCCAAGCTTTTGAGG } \\
\text { R: CTGCAAAAGATTGTTTGGCAGA }\end{array}$ & 300 \\
\hline iceA1 & $\begin{array}{l}\text { F: GTGTTTTTAACCAAAGTATC } \\
\text { R: CTATAGCCASTYTCTTTGCA }\end{array}$ & 247 \\
\hline ice A2 & $\begin{array}{l}\text { F: GTTGGGTATATCACAATTTAT } \\
\text { R: TTRCCCTATTTTCTAGTAGGT }\end{array}$ & $229 / 334$ \\
\hline oipA & $\begin{array}{l}\text { F: GTTTTTGATGCATGGGATTT } \\
\text { R: GTGCATCTCTTATGGCTTT }\end{array}$ & 401 \\
\hline
\end{tabular}

${ }^{*}$ F: forward.

${ }^{* *} \mathrm{R}$ : reverse.

H. pylori have been gotten from the GenBank Database of the National Center for Biotechnology Information (NCBI) (GenBank: AY714224.1). The CLS sequence viewer software (Version 6/4) has been used for alignments of the $u r e B$ gene. Forward and reverse primers have been designed based on the protected area in these sequences. Thermodynamic properties of designed primers were studied using the Gene Runner software (Version 3.05). In order to ensure the specificity of designed primers, the Basic Logical Alignment Search Tool (BLAST) service has been used. The forward primer sequence was UreB: $5^{\prime}-$ CTTAGCGTGGGTCCTGCTAC- $3^{\prime}$ and the reverse primer sequence was UreB: $5^{\prime}$-TGGTGGCACACCATAAGCAT-3'. The gene product was $635 \mathrm{bp}$. PCR reactions were performed in a final volume of $50 \mu \mathrm{L}$ containing $5 \mu \mathrm{L} 10 \times$ buffer + $\mathrm{MgCl}_{2}, 2 \mathrm{mM}$ dNTP, 2-unit Taq DNA polymerase, $100 \mathrm{ng}$ genomic DNA as a template, and 25 picomoles of each primer. PCR was performed using a thermal cycler (Eppendorf Co., Germany) under the following conditions: an initial denaturation for 10 minutes at $94^{\circ} \mathrm{C} ; 35$ cycles for 1 minute at $94^{\circ} \mathrm{C}$, 1 minute at $57^{\circ} \mathrm{C}, 1$ minute at $72^{\circ} \mathrm{C}$, and a final extension at $72^{\circ} \mathrm{C}$ for 10 minutes. The PCR products were electrophoresed through $1.5 \%$ agarose gels (Fermentas, Germany) containing ethidium bromide. A DNA ladder (Fermentas Co., Germany) was used to detect the molecular weight of observed bands under a UV lamp. All tests were performed in triplicate. Samples inoculated with $H$. pylori were used as positive controls.
2.4. Genotyping of Helicobacter pylori. Presence of the oipA, cagA and the genotypes of $v a c A(s 1 a, s 1 b, s 1 c, m 1 a, m 1 b$, and $m 2$ ) and iceA (iceA1 and iceA2) alleles were determined by PCR. The primer sequences are shown in Table $1[17,20,26-$ 30].

The PCR was performed in a total volume of $50 \mu \mathrm{L}$ containing $1 \mu \mathrm{M}$ of each primer, $1 \mu \mathrm{L}$ of genomic DNA (approximately $200 \mathrm{ng}$ ), $1 \mathrm{mM}$ of dNTPs mix (Invitrogen), $2 \mathrm{mM}$ of $\mathrm{Mgcl}_{2}$, and $0.05 \mathrm{U} / \mu \mathrm{L}$ Taq DNA polymerase (Invitrogen). PCR amplifications were performed in an automated thermal cycler (Biometra Co., Germany). The following cycle conditions were used for PCR amplification: for vacA: 32 cycles of $45 \mathrm{~s}$ at $95^{\circ} \mathrm{C}, 50 \mathrm{~s}$ at $64^{\circ} \mathrm{C}$, and $70 \mathrm{~s}$ at $72^{\circ} \mathrm{C}$; for $\operatorname{cagA}$ : $1 \mathrm{~min}$ at $94^{\circ} \mathrm{C}, 1 \mathrm{~min}$ at $56^{\circ} \mathrm{C}$, and $1 \mathrm{~min}$ at $72^{\circ} \mathrm{C}$; for ice $A$ : $1 \mathrm{~min}$ at $94^{\circ} \mathrm{C}, 1 \mathrm{~min}$ at $56^{\circ} \mathrm{C}$, and $1 \mathrm{~min}$ at $72^{\circ} \mathrm{C}$; and, finally, for oipA: $1 \mathrm{~min}$ at $94^{\circ} \mathrm{C}, 1 \mathrm{~min}$ at $56^{\circ} \mathrm{C}$, and $1 \mathrm{~min}$ at $72^{\circ} \mathrm{C}$. All runs included one negative DNA control consisting of PCR grade water and two or more positive controls (26695, J99, SS1, Tx30, 88-23, and 84-183). The amplified products were visualized using ethidium bromide staining after gel electrophoresis of $10 \mu \mathrm{L}$ of the final reaction mixture in $1.5 \%$ agarose.

2.5. Statistical Analysis. Data was transferred to Microsoft Excel spreadsheet (Microsoft Corp., Redmond, WA, USA) for analysis. Using SPSS 16.0 statistical software (SPSS Inc., Chicago, IL, USA), Chi-square test and Fisher's exact twotailed test analysis were performed and differences were 


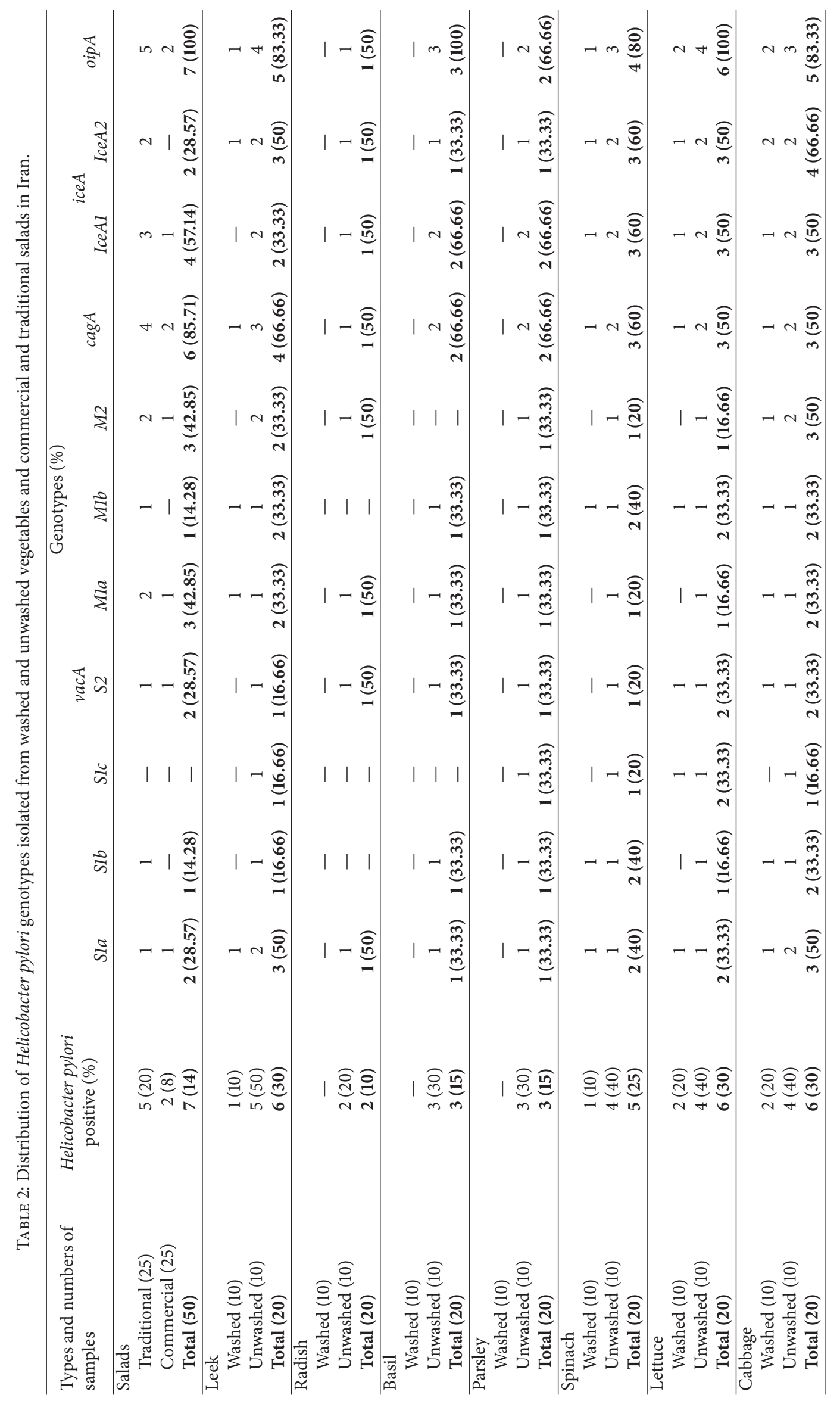




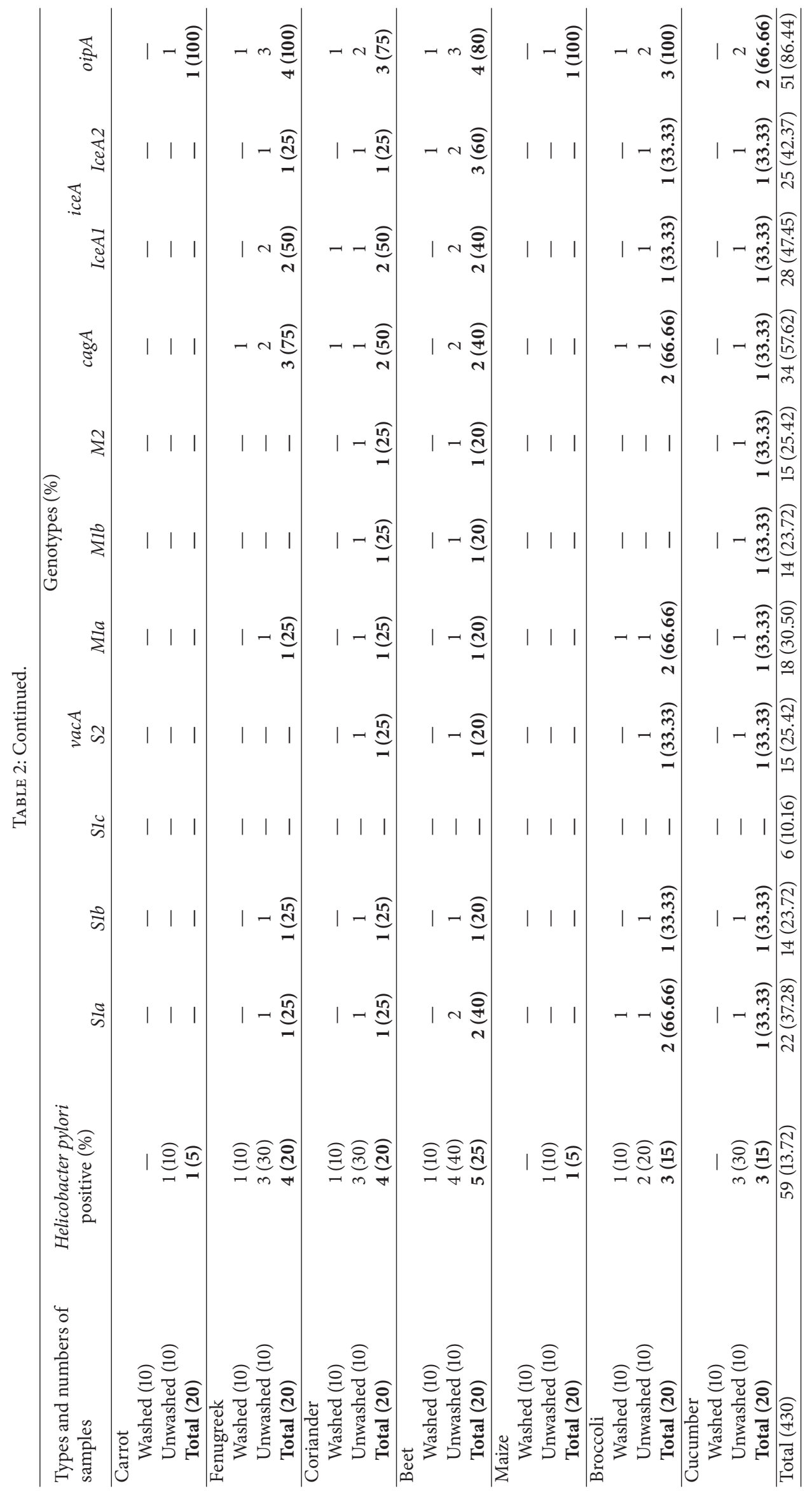


considered significant at values of $P<0.05$. Distribution of genotypes and antimicrobial resistance properties of $H$. pylori isolated from washed and unwashed vegetables and commercial and traditional salads were statistically analyzed.

\section{Results}

All of the vegetable and salad samples were examined using the culture and PCR techniques. From 380 vegetable and 50 salad samples, $52(13.68 \%)$ and $7(14 \%)$ were positive for H. pylori, respectively (Table 2 ). There were statistically significant differences in the incidence of bacteria in washed and unwashed vegetables and traditional and commercial salad samples $(P<0.01)$. We found that the leek, lettuce, and cabbage samples had the highest incidence of $H$. pylori (Table 2). There were no positive results for pepper, turnip, garlic, chive, and scallion samples. Genotype oipA (86.44\%) was the most commonly detected genotype in $H$. pylori isolates, followed by cagA (57.625) (Table 2). Genotypes vacA sla $(37.28 \%)$ and $v a c A$ mla $(30.50 \%)$ regions had the highest incidence in $v a c A$ genotypes, while vacA slc region (10.16\%) had the lowest incidence (Table 2). A significant difference was found in the incidence of oipA and other genotypes $(P<$ $0.05)$.

Twenty-five and forty-two percent of $H$. pylori strains harbored both mla and $\mathrm{m} 2$, while $22.03 \%$ harbored both $\mathrm{m} 1 \mathrm{~b}$ and $\mathrm{m} 2$ (Table 3 ). Frequency of $\operatorname{cag} A$, oipA, and both ice $A 1$ and ice $A 2$ genotypes was $57.62 \%, 86.44 \%$, and $40.67 \%$, respectively (Table 3 ).

Forty different genotypic combinations are shown in Table 4 . The most commonly detected combined genotypes were sla/cagA+/iceA1/oipA+ (33.89\%), sla/cagA+/iceA2/ oipA (30.50\%), mla/cagA+/iceAl/oipA+ (28.81\%), mla/cagA+/ iceA2/oipA+ (25.42\%), and s2/cagA+/iceA1/oipA+ (25.42\%).

Descriptions of the seasonal profiles of $H$. pylori isolates are shown in Table 5. Samples which were collected in the spring had the highest incidence $(71.18 \%)$ of $H$. pylori, while those collected in summer had the lowest incidence $(3.38 \%)$. There were statistically significant differences $(P<0.01)$ in the incidence of bacteria in spring and other seasons.

Distributions of antimicrobial resistance pattern of $H$. pylori strains are shown in Table 6. The highest levels of antibiotic resistance of the $H$. pylori strains isolated from vegetable and salad samples were found against metronidazole (77.96\%), followed by amoxicillin $(67.79 \%)$ and ampicillin $(61.01 \%)$. Bacterial strains of our study were susceptible to levofloxacin, rifampin, trimethoprim, cefsulodin, and spiramycin. We found statistically significant differences in the incidence of bacterial antibiotic resistance against metronidazole, streptomycin, furazolidone, and rifampin $(P<0.05)$.

\section{Discussion}

Totally, $13.72 \%$ of vegetable and salad samples of our investigation were contaminated with $H$. pylori. High prevalence of H. pylori in clinical samples was reported from Scandinavia, Turkey, Japan, Pakistan, South America, and England [31], while low prevalence was reported from Canada [29]. Our
TABLE 3: Distribution of Helicobacter pylori genotypes isolated from vegetables and salad samples in Iran.

\begin{tabular}{|c|c|}
\hline Genotypes & Prevalence (\%) \\
\hline \multicolumn{2}{|c|}{ vacA } \\
\hline Mlasla & $16\left(27.11^{*}\right)$ \\
\hline Mlaslb & $14(23.72)$ \\
\hline M1bsla & $13(22.03)$ \\
\hline M1bs1b & $14(23.72)$ \\
\hline Mlaslc & $4(6.77)$ \\
\hline M1bsic & $2(3.38)$ \\
\hline M2sla & $14(23.72)$ \\
\hline M2slb & $11(18.64)$ \\
\hline M2s1c & $3(5.08)$ \\
\hline M2s2 & $15(25.42)$ \\
\hline Mlas2 & $13(22.03)$ \\
\hline M1bs2 & $11(18.64)$ \\
\hline M1am2 & $15(25.42)$ \\
\hline M1bm2 & $13(22.03)$ \\
\hline \multicolumn{2}{|c|}{$\operatorname{cag} A$} \\
\hline CagA+ & $34(57.62)$ \\
\hline CagA- & $25(42.37)$ \\
\hline \multicolumn{2}{|c|}{$i c e A$} \\
\hline IceAl & $28(47.45)$ \\
\hline IceA2 & $25(42.37)$ \\
\hline IceA1 IceA2 & $24(40.67)$ \\
\hline \multicolumn{2}{|c|}{ oipA } \\
\hline OipA+ & $51(86.44)$ \\
\hline OipA- & $8(13.55)$ \\
\hline
\end{tabular}

${ }^{*}$ Percentage of positive genes from total 59 positive samples.

work has identified marked seasonality in the incidence of $H$. pylori isolated from vegetable and salad samples. $H$. pylori isolates had the highest incidence in spring season (71.18\%). Moshkowitz et al. (1994) [32] reported that the frequency of $H$. pylori infection in dyspeptic patients in Israel is significantly increased in the humid and rainfall months and decreases in the summer, which is similar to our results. Similar seasonal distributions of $H$. pylori were reported previously [33, 34].

Leek, lettuce, and cabbage were the most commonly contaminated samples in our investigation as they are grown in manure rich soil and thus can easily be infected. Differences in amount of activated water (AW), pH, and hygienic conditions during processing of vegetable and salad samples caused high differences in the incidence of $H$. pylori in our study. Also, the role of infected staffs as sources of $H$. pylori infection is so important [11]. The main reason for the high distribution of $H$. pylori in commercial salad samples is the fact that maybe some food safety and quality standards (good agricultural practices (GAPs), good manufacturing practices (GMPs), and the hazard analysis and critical control point (HACCP) system need to be applied and performed in most of the Iranian food units to control growth, proliferation, and survival of bacteria during harvesting, distribution, and storage periods. 
TABle 4: Combined vacA, cagA, iceA, and oipA genotypes of Helicobacter pylori isolated from salads and vegetables in Iran.

\begin{tabular}{|c|c|}
\hline Combined genotypes & $\operatorname{Total}\left(59^{*}\right)(\%)$ \\
\hline sla/cagA+/iceA1/oipA+ & $20(33.89)$ \\
\hline slb/cagA+/iceA1/oipA+ & $11(18.64)$ \\
\hline slc/cagA+/iceAl/oipA+ & $6(10.16)$ \\
\hline sla/cagA+/iceA2/oipA+ & $18(30.50)$ \\
\hline slb/cagA+/iceA2/oipA+ & $12(20.33)$ \\
\hline slc/cagA+/iceA2/oipA+ & $5(8.47)$ \\
\hline sla/cagA-/iceAl/oipA+ & $11(18.64)$ \\
\hline slb/cagA-/iceAl/oipA+ & $8(13.55)$ \\
\hline slc/cagA-/iceAl/oipA+ & $4(6.77)$ \\
\hline sla/cagA-/iceA2/oipA+ & $10(16.94)$ \\
\hline slb/cagA-/iceA2/oipA+ & $7(11.86)$ \\
\hline slc/cagA-/iceA2/oipA+ & $4(6.77)$ \\
\hline sla/cagA+/iceAl/oipA- & $6(10.16)$ \\
\hline slb/cagA+/iceA1/oipA- & $3(5.08)$ \\
\hline slc/cagA+/iceA1/oipA- & $2(3.38)$ \\
\hline s2/cagA+/iceA1/oipA+ & $15(25.42)$ \\
\hline s2/cagA+/iceA2/oipA+ & $14(23.72)$ \\
\hline s2/cagA-/iceA1/oipA+ & $12(20.33)$ \\
\hline s2/cagA-/iceA2/oipA+ & $10(16.94)$ \\
\hline s2/cagA-/iceA2/oipA- & $6(10.16)$ \\
\hline $\mathrm{s} 2 /$ cagA +/iceA2/oipA- & $7(11.86)$ \\
\hline s2/cagA+/iceA1/oipA- & $8(13.55)$ \\
\hline mla/cagA+/iceAl/oipA+ & $17(28.81)$ \\
\hline $\mathrm{mlb} / \mathrm{cagA}+$ /iceAl/oipA+ & $13(22.03)$ \\
\hline $\mathrm{mla} / \mathrm{cagA}+/ \mathrm{iceA} 2 /$ oipA + & $15(25.42)$ \\
\hline $\mathrm{mlb} / \mathrm{cagA}+/$ iceA2/oipA+ & $12(20.33)$ \\
\hline mla/cagA-/iceA1/oipA+ & $14(23.72)$ \\
\hline $\mathrm{mlb} / \mathrm{cagA}-/$ iceAl/oipA+ & $11(18.64)$ \\
\hline $\mathrm{mla} /$ cagA-/iceA2/oipA+ & $12(20.33)$ \\
\hline $\mathrm{mlb} / \mathrm{cag} \mathrm{A}-/$ iceA2/oipA+ & $10(16.94)$ \\
\hline $\mathrm{mla} / \mathrm{cagA}+/$ iceAl/oipA- & $5(8.47)$ \\
\hline mlb/cagA+/iceA2/oipA- & $3(5.08)$ \\
\hline $\mathrm{m} 2 / \mathrm{cagA}+$ iceA1/oipA+ & $14(23.72)$ \\
\hline $\mathrm{m} 2 / \mathrm{cagA}+/$ iceA2/oipA+ & $13(22.03)$ \\
\hline $\mathrm{m} 2 / \mathrm{cag} \mathrm{A}+/$ iceA2/oipA- & $5(8.47)$ \\
\hline $\mathrm{m} 2 /$ cagA+/iceA1/oipA- & $6(10.16)$ \\
\hline $\mathrm{m} 2 /$ cagA-/iceA1/oipA+ & $11(18.64)$ \\
\hline $\mathrm{m} 2 /$ cagA-/iceA2/oipA+ & $10(16.94)$ \\
\hline $\mathrm{m} 2 /$ cagA-/iceA2/oipA- & $3(5.08)$ \\
\hline $\mathrm{m} 2 /$ cagA-/iceA1/oipA- & $4(6.77)$ \\
\hline
\end{tabular}

${ }^{*}$ Total positive samples.

TABLE 5: Seasonal distribution of Helicobacter pylori isolated from washed and unwashed vegetables and commercial and traditional salads in Iran.

\begin{tabular}{|c|c|c|c|c|}
\hline \multirow{2}{*}{ Types and numbers of positive samples } & \multicolumn{4}{|c|}{ Seasonal distribution (\%) } \\
\hline & Winter & Summer & Autumn & Spring \\
\hline \multicolumn{5}{|l|}{ Salads } \\
\hline Traditional $\left(5^{*}\right)$ & $1(20)$ & - & $1(20)$ & $3(60)$ \\
\hline Commercial (2) & - & - & - & $2(100)$ \\
\hline Total (7) & $1(14.28)$ & - & $1(14.28)$ & $5(71.42)$ \\
\hline \multicolumn{5}{|l|}{ Vegetables } \\
\hline Washed (10) & $2(20)$ & - & $1(10)$ & $7(70)$ \\
\hline Unwashed (42) & $6(14.28)$ & $2(4.76)$ & $4(9.52)$ & $30(71.42)$ \\
\hline Total (52) & $8(15.38)$ & $2(3.84)$ & $5(9.61)$ & $37(71.15)$ \\
\hline \multicolumn{5}{|l|}{ Total } \\
\hline Vegetables and salads (59) & $9(15.25)$ & $2(3.38)$ & $6(10.16)$ & $42(71.18)$ \\
\hline
\end{tabular}

${ }^{*}$ Numbers of positive samples. 


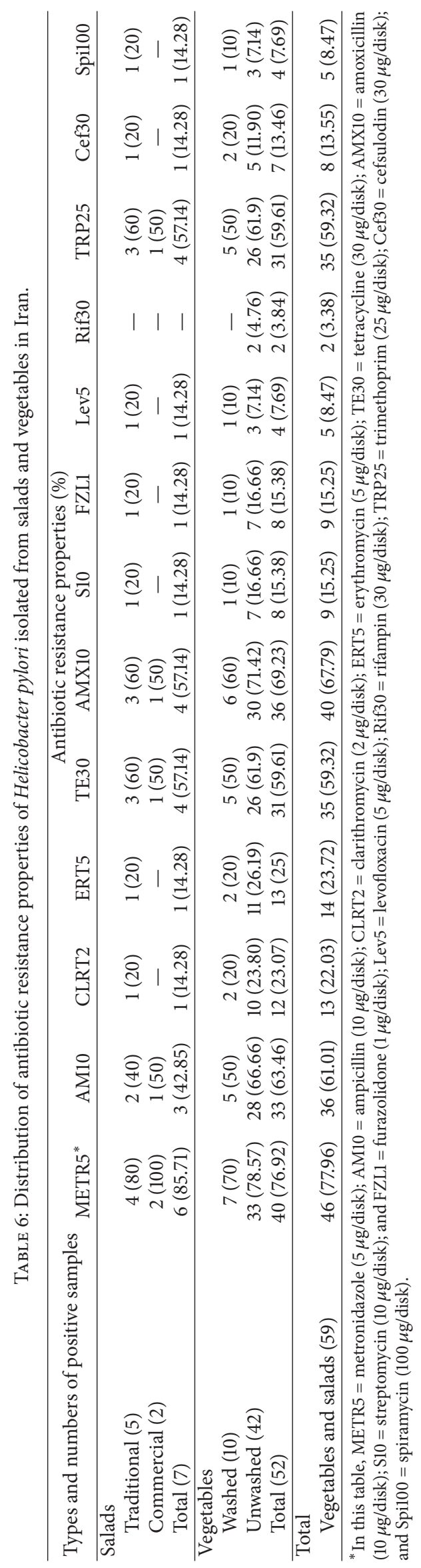


High incidence of $H$. pylori in uncooked vegetables that had been irrigated with water contaminated with sewage was reported previously $[35,36]$. Frequent consumption of raw vegetables was associated with likelihood of $H$. pylori infection [37]. Also, individuals who consume vegetables are more likely to acquire $H$. pylori [38]. Foods with water activity higher than 0.96 and $\mathrm{pH}$ from 4.9 to 9.0 (like vegetables) theoretically provide conditions for the survival of $H$. pylori [39].

The most commonly detected virulence genes in $\mathrm{H}$. pylori strains of our study were oipA $(86.44 \%)$, cagA $(57.62 \%)$, iceA1 (47.45\%), and iceA2 (42.37\%). High presence of these genes in clinical samples has been reported previously from Japan [40], Turkey [41], Nigeria [42], and the United States [43]. These virulence genes are responsible for cytotoxin production [44], interleukin-8 (IL-8) construction [45, 46], vacuolization and apoptosis in gastric epithelial cells $[13,14]$, adhesion to gastric epithelial cells, and inflammatory effects $[15,47]$.

Alleles vacA sla (37.28\%) and iceA1 (47.45\%) were the most commonly detected genotypes in $v a c A$ and iceA positive samples of our study, respectively. VacA $m 1 a / s 1$ (27.11\%), vacA $\mathrm{m} 2 / \mathrm{s} 2$ (25.42\%), vacA $\mathrm{mla} / \mathrm{m} 2$ (25.42\%), and iceAl/iceA2 (40.67\%) were the most commonly detected genotypes in our study. There were no previously published data about the genotyping of $H$. pylori in vegetables, salads, and even other types of foods. Various genotypes of $v a c A$ strains were the most commonly detected genotypes in the studies of Linpisarn et al. (2007) (Thailand) [48], López-Vidal et al. (2008) (Mexico) [49], and Rudi et al. (1998) (Germany) [50]. The high presence of $v a c A$ sla/m2 genotypes has been reported previously from Iran [11] and Germany [50] but far different results have been reported from Thailand [48] and Mexico [49].

Bacterial strains of our study were resistant to the majority of tested antibiotics. We found that bacterial strains exhibited the highest level of resistance to metronidazole (77.96\%), amoxicillin (67.79\%), ampicillin (61.01\%), and tetracycline $(59.32 \%)$. The high antibiotic resistance to these drugs detected in our study indicates that irregular and unauthorized use of them may have occurred in Iran. Similarly, metronidazole, amoxicillin, ampicillin, and tetracycline resistance profiles have been reported previously [51, 52]. Indian strains of $H$. pylori had the highest antibiotic resistance against metronidazole (77.9\%), clarithromycin (44.7\%), and amoxicillin (32.8\%) [52], which was similar to our results. Bang et al. (2007) [25] found that the H. pylori isolates had the high antibiotic resistance to metronidazole (34.7\%), clarithromycin (16.7\%), and amoxicillin (11.8\%). Low antibiotic resistance of $H$. pylori strains against levofloxacin, rifampin, trimethoprim, cefsulodin, and spiramycin may be due to the regular and low prescription of these antibiotics.

H. pylori isolates from African countries like Senegal and Nigeria, Asian countries like India, Taiwan, China, Iran, Egypt, Saudi Arabia, and Thailand, and South American countries like Argentina, Brazil, and Colombia had the highest antibiotic resistance to metronidazole, followed by clarithromycin, amoxicillin, quinolones, tetracycline, and furazolidone [30], which was similar to our results.

The above data highlight large differences in the prevalence of $H$. pylori in different studies, as well as differences in virulence genes, genotypes, and antibiotic resistance patterns in the clinical samples. This could be related to differences in the type of sample tested (stool, gastric biopsy, saliva, and food), number of samples, method of sampling, experimental methodology, geographical area, antibiotic prescription preference among clinicians, antibiotic availability, and climate differences in the areas where the samples were collected, which would have differed in each study.

\section{Conclusions}

In conclusion, vegetable and salad samples harbor $H$. pylori similar in genotype of the vacA, cagA, oipA, and iceA alleles to isolates recovered from humans. Also, there was a high similarity in the genotyping pattern of $H$. pylori DNA among vegetable and salad samples and human specimens of other investigations suggest that vegetables and salads are the sources of the bacteria and that they entered the human population in a period of time. On the other hand, diversity of $H$. pylori genotypes in vegetable and salad samples with the clinical isolates of other studies suggested that consumption of contaminated vegetables and salads with $H$. pylori strains may be a threat to human health. Our findings should raise awareness about antibiotic resistance in $H$. pylori strains in Iran. Clinicians should exercise caution when prescribing antibiotics, especially during the spring season. Our data showed that conventional ways to wash vegetables cannot reduce their contamination.

\section{Conflict of Interests}

The authors declare that they have no conflict of interests.

\section{Acknowledgments}

The authors would like to thank Professor F. Hemmatzadeh at Adelaide University, Australia, Professor M. Ameri at the Department of Clinical Pathology, Wyeth Research, Chazy, New York, USA, and Professor E. Rahimi, Professor A. Shakerian, and Mr. M. Momeni at the Biotechnology Research Center of the Islamic Azad University of Shahrekord for their important technical and clinical support.

\section{References}

[1] L. M. Pérez, F. Codony, D. López Leyton, M. Fittipaldi, B. Adrados, and J. Morató, "Quantification of Helicobacter pylori levels in soil samples from public playgrounds in Spain," Journal of Zhejiang University Science B, vol. 11, no. 1, pp. 27-29, 2010.

[2] Y. Lu, T. E. Redlinger, R. Avitia, A. Galindo, and K. Goodman, "Isolation and genotyping of Helicobacter pylori from untreated municipal wastewater," Applied and Environmental Microbiology, vol. 68, no. 3, pp. 1436-1439, 2002. 
[3] M. Tabatabaei, "Application of molecular and cultural methods for identification of Helicobacter SPP. In different animal sources," Global Veterinaria, vol. 8, no. 3, pp. 292-297, 2012.

[4] H. G. Safaei, E. Rahimi, A. Zandi, and A. Rashidipour, "Helicobacter pylori as a zoonotic infection: the detection of $H$. pylori antigens in the milk and faeces of cows," Journal of Research in Medical Sciences, vol. 16, pp. 184-187, 2011.

[5] T. Falsafi, N. Valizadeh, M. Najafi et al., "Culture of Helicobacter pylori from stool samples in children," Canadian Journal of Microbiology, vol. 53, no. 3, pp. 411-416, 2007.

[6] S. M. Kelly, M. C. L. Pitcher, S. M. Farmery, and G. R. Gibson, "Isolation of Helicobacter pylori from feces of patients with dyspepsia in the United Kingdom," Gastroenterology, vol. 107, no. 6, pp. 1671-1674, 1994.

[7] B. J. Marshall and H. M. Windsor, “The relation of Helicobacter pylori to gastric adenocarcinoma and lymphoma: pathophysiology, epidemiology, screening, clinical presentation, treatment, and prevention," Medical Clinics of North America, vol. 89, no. 2, pp. 313-344, 2005.

[8] F. F. Vale and J. M. B. Vítor, "Transmission pathway of Helicobacter pylori: does food play a role in rural and urban areas?" International Journal of Food Microbiology, vol. 138, no. 1-2, pp. 1-12, 2010.

[9] F. Naja, N. Kreiger, and T. Sullivan, "Helicobacter pylori infection in Ontario: prevalence and risk factors," Canadian Journal of Gastroenterology, vol. 21, no. 8, pp. 501-506, 2007.

[10] D. R. Cave, "How is helicobacter pylori transmitted?" Gastroenterology, vol. 113, no. 6, pp. S9-S14, 1997.

[11] H. Momtaz, N. Souod, H. Dabiri, and M. Sarshar, "Study of Helicobacter pylori genotype status in saliva, dental plaques, stool and gastric biopsy samples," World Journal of Gastroenterology, vol. 18, no. 17, pp. 2105-2111, 2012.

[12] K. Ben Mansour, C. Fendri, M. Zribi et al., "Prevalence of Helicobacter pylori vacA, cagA, iceA and oipA genotypes in Tunisian patients," Annals of Clinical Microbiology and Antimicrobials, vol. 9, article 10, 2010.

[13] S. R. Blanke, "Micro-managing the executioner: pathogen targeting of mitochondria," Trends in Microbiology, vol. 13, no. 2, pp. 64-71, 2005.

[14] T. L. Cover, U. S. Krishna, D. A. Israel, and R. M. Peek Jr., "Induction of gastric epithelial cell apoptosis by Helicobacter pylori vacuolating cytotoxin," Cancer Research, vol. 63, no. 5, pp. 951-957, 2003.

[15] Y. Yamaoka, R. Reddy, and D. Y. Graham, "Helicobacter pylori virulence factor genotypes in children in the United States: Clues about genotype and outcome relationships," Journal of Clinical Microbiology, vol. 48, no. 7, pp. 2550-2551, 2010.

[16] G. H. Scholte, L. J. van Doorn, A. Cats et al., "Genotyping of Helicobacter pylori in paraffin-embedded gastric biopsy specimens: relation to histological parameters and effects on therapy Genotyping of $H$. pylori in gastric biopsy specimens," The American Journal of Gastroenterology, vol. 97, pp. 1687-1695, 2002.

[17] J. Wang, D. S. Chi, J. J. Laffan et al., "Comparison of cytotoxin genotypes of Helicobacter pylori in stomach and saliva," Digestive Diseases and Sciences, vol. 47, no. 8, pp. 1850-1856, 2002.

[18] J. C. Atherton, P. Cao, R. M. Peek Jr., M. K. R. Tummuru, M. J. Blaser, and T. L. Cover, "Mosaicism in vacuolating cytotoxin alleles of Helicobacter pylori. Association of specific vacA types with cytotoxin production and peptic ulceration," The Journal of Biological Chemistry, vol. 270, no. 30, pp. 17771-17777, 1995.
[19] M. J. Matteo, G. Granados, C. V. Pérez, M. Olmos, C. Sanchez, and M. Catalano, "Helicobacter pylori cag pathogenicity island genotype diversity within the gastric niche of a single host," Journal of Medical Microbiology, vol. 56, no. 5, pp. 664-669, 2007.

[20] F. Kauser, M. A. Hussain, I. Ahmed et al., "Comparing genomes of Helicobacter pylori strains from the high-altitude desert of Ladakh, India," Journal of Clinical Microbiology, vol. 43, pp. 1538-1545, 2005.

[21] Y. Yamaoka, "Pathogenesis of Helicobacter pylori-related gastroduodenal diseases from molecular epidemiological studies," Gastroenterology Research and Practice, vol. 2012, Article ID 371503, 9 pages, 2012.

[22] Y. Yamaoka, D. H. Kwon, and D. Y. Graham, "A $\mathrm{M}_{r} 34,000$ proinflammatory outer membrane protein (oipA) of Helicobacter pylori," Proceedings of the National Academy of Sciences of the United States of America, vol. 97, no. 13, pp. 7533-7538, 2000.

[23] L. Boyanova and I. Mitov, "Geographic map and evolution of primary Helicobacter pylori resistance to antibacterial agents," Expert Review of Anti-Infective Therapy, vol. 8, no. 1, pp. 59-70, 2010.

[24] F. Mégraud, "Helicobacter pylori antibiotic resistance: prevalence, importance, and advances in testing," Gut, vol. 53, no. 9, pp. 1374-1384, 2004.

[25] S. Y. Bang, D. S. Han, C. S. Eun et al., "Changing patterns of antibiotic resistance of Helicobacter pylori in patients with peptic ulcer disease," Korean Journal of Gastroenterology, vol. 50, no. 6, pp. 356-362, 2007.

[26] Clinical and Laboratory Standards Institute (CLSI), "Performance standards for antimicrobial susceptibility testing; twenty-second informational supplement," CLSI Document M100-S22, CLSI, Wayne, Pa, USA, 2012.

[27] M. K. R. Tummuru, T. L. Cover, and M. J. Blaser, "Cloning and expression of a high-molecular-mass major antigen of Helicobacter pylori: evidence of linkage to cytotoxin production," Infection and Immunity, vol. 61, no. 5, pp. 1799-1809, 1993.

[28] S. Yamazaki, A. Yamakawa, T. Okuda et al., "Distinct diversity of vacA, cagA, and cagE genes of Helicobacter pylori associated with peptic ulcer in Japan," Journal of Clinical Microbiology, vol. 43, no. 8, pp. 3906-3916, 2005.

[29] I. Segal, A. Otley, R. Issenman et al., "Low prevalence of Helicobacter pylori infection in Canadian children: a crosssectional analysis," Canadian Journal of Gastroenterology, vol. 22, pp. 485-489, 2008.

[30] R. H. Hunt, S. D. Xiao, F. Megraud et al., "World Gastroenterology Organization (WGO) global guideline," in Helicobacter Pylori in Developing Countries, pp. 9-10, 2010.

[31] F. Jafari, L. Shokrzadeh, H. Dabiri et al., "vacA genotypes of Helicobacter pylori in relation to cagA status and clinical outcomes in Iranian populations," Japanese Journal of Infectious Diseases, vol. 61, no. 4, pp. 290-293, 2008.

[32] M. Moshkowitz, F. M. Konikoff, N. Arber et al., "Seasonal variation in the frequency of Helicobacter pylori infection: a possible cause of the seasonal occurrence of peptic ulcer disease," The American Journal of Gastroenterology, vol. 89, no. 5, pp. 731-733, 1994.

[33] R. Manfredini, R. de Giorgio, M. H. Smolensky et al., "Seasonal pattern of peptic ulcer hospitalizations: analysis of the hospital discharge data of the Emilia-Romagna region of Italy," BMC Gastroenterology, vol. 10, article 37, 2010. 
[34] S. Thirumurthi and D. Y. Graham, "Helicobacter pylori infection in India from a western perspective," Indian Journal of Medical Research, vol. 136, no. 4, pp. 549-562, 2012.

[35] R. J. Hopkins, P. A. Vial, C. Ferreccio et al., "Seroprevalence of Helicobacter pylori in Chile: vegetables may serve as one route of transmission," The Journal of Infectious Diseases, vol. 168, pp. 222-226, 1993.

[36] Y. T. H. P. van Duynhoven and R. de Jonge, "Transmission of Helicobacter pylori: a role for food?" Bulletin of the World Health Organization, vol. 79, no. 5, pp. 455-460, 2001.

[37] K. J. Goodman, P. Correa, H. J. Tenganá Aux et al., "Helicobacter pylori infection in the Colombian Andes: a population- based study of transmission pathways," American Journal of Epidemiology, vol. 144, no. 3, pp. 290-299, 1996.

[38] S. Y. Chen, T. S. Liu, X. M. Fan et al., "Epidemiological study of Helicobacter pylori infection and its risk factors in Shanghai," Zhonghua Yi Xue Za Zhi, vol. 85, no. 12, pp. 802-806, 2005.

[39] X. Jiang and M. P. Doyle, "Effect of environmental and substrate factors on survival and growth of Helicobacter pylori," Journal of Food Protection, vol. 61, no. 8, pp. 929-933, 1998.

[40] T. Sasaki, I. Hirai, R. Izurieta et al., "Analysis of Helicobacter pylori genotype in stool specimens of asymptomatic people," Laboratory Medicine, vol. 40, no. 7, pp. 412-414, 2009.

[41] T. Nagiyev, E. Yula, B. Abayli, and F. Koksal, "Prevalence and genotypes of Helicobacter pylori in gastric biopsy specimens from patients with gastroduodenal pathologies in the Cukurova region of Turkey," Journal of Clinical Microbiology, vol. 47, no. 12, pp. 4150-4153, 2009.

[42] S. I. Smith, C. Kirsch, K. S. Oyedeji et al., "Prevalence of Helicobacter pylori vacA, cagA and iceA genotypes in Nigerian patients with duodenal ulcer disease," Journal of Medical Microbiology, vol. 51, no. 10, pp. 851-854, 2002.

[43] C. Nogueira, C. Figueiredo, F. Carneiro et al., "Helicobacter pylori genotypes may determine gastric histopathology," American Journal of Pathology, vol. 158, pp. 647-654, 2001.

[44] P. J. Jenks, F. Mégraud, and A. Labigne, "Clinical outcome after infection with Helicobacter pylori does not appear to be reliably predicted by the presence of any of the genes of the cag pathogenicity island," Gut, vol. 43, no. 6, pp. 752-758, 1998.

[45] J. E. Crabtree, N. Figura, J. D. Taylor, M. Bugnoli, D. Armellini, and D. S. Tompkins, "Expression of 120 kilodalton protein and cytotoxicity in Helicobacter pylori," Journal of Clinical Pathology, vol. 45, no. 8, pp. 733-734, 1992.

[46] M. J. Blaser, G. I. Perez-Perez, H. Kleanthous et al., "Infection with Helicobacter pylori strains possessing cagA is associated with an increased risk of developing adenocarcinoma of the stomach," Cancer Research, vol. 55, no. 10, pp. 2111-2115, 1995.

[47] L.-J. Van Doorn, C. Figueiredo, R. Sanna et al., "Clinical relevance of the cagA, vacA, and iceA status of Helicobacter pylori," Gastroenterology, vol. 115, no. 1, pp. 58-66, 1998.

[48] S. Linpisarn, W. Suwan, N. Lertprasertsuk et al., "Helicobacter pylori cagA, vacA and iceA genotypes in northern Thai patients with gastric disease," Southeast Asian Journal of Tropical Medicine and Public Health, vol. 38, no. 2, pp. 356-362, 2007.

[49] Y. López-Vidal, S. Ponce-de-León, G. Castillo-Rojas, R. BarretoZúñiga, and A. Torre-Delgadillo, "High diversity of vacA and cagA Helicobacter pylori genotypes in patients with and without gastric cancer," PLoS ONE, vol. 3, no. 12, Article ID e3849, 2008.

[50] J. Rudi, C. Kolb, M. Maiwald et al., "Diversiyt of Helicobacter pylori vacA and cagA genes and relationship to VacA and
CagA protein expression, cytotoxin production, and associated disease," Journal of Clinical Microbiology, vol. 36, no. 4, pp. 944948, 1998.

[51] O. Secka, D. E. Berg, M. Antonio et al., "Antimicrobial susceptibility and resistance patterns among Helicobacter pylori strains from The Gambia, West Africa," Antimicrobial Agents and Chemotherapy, vol. 57, no. 3, pp. 1231-1237, 2013.

[52] S. P. Thyagarajan, P. Ray, B. K. Das et al., "Geographical difference in antimicrobial resistance pattern of Helicobacter pylori clinical isolates from Indian patients: multicentric study," Journal of Gastroenterology and Hepatology, vol. 18, pp. 13731378, 2003. 

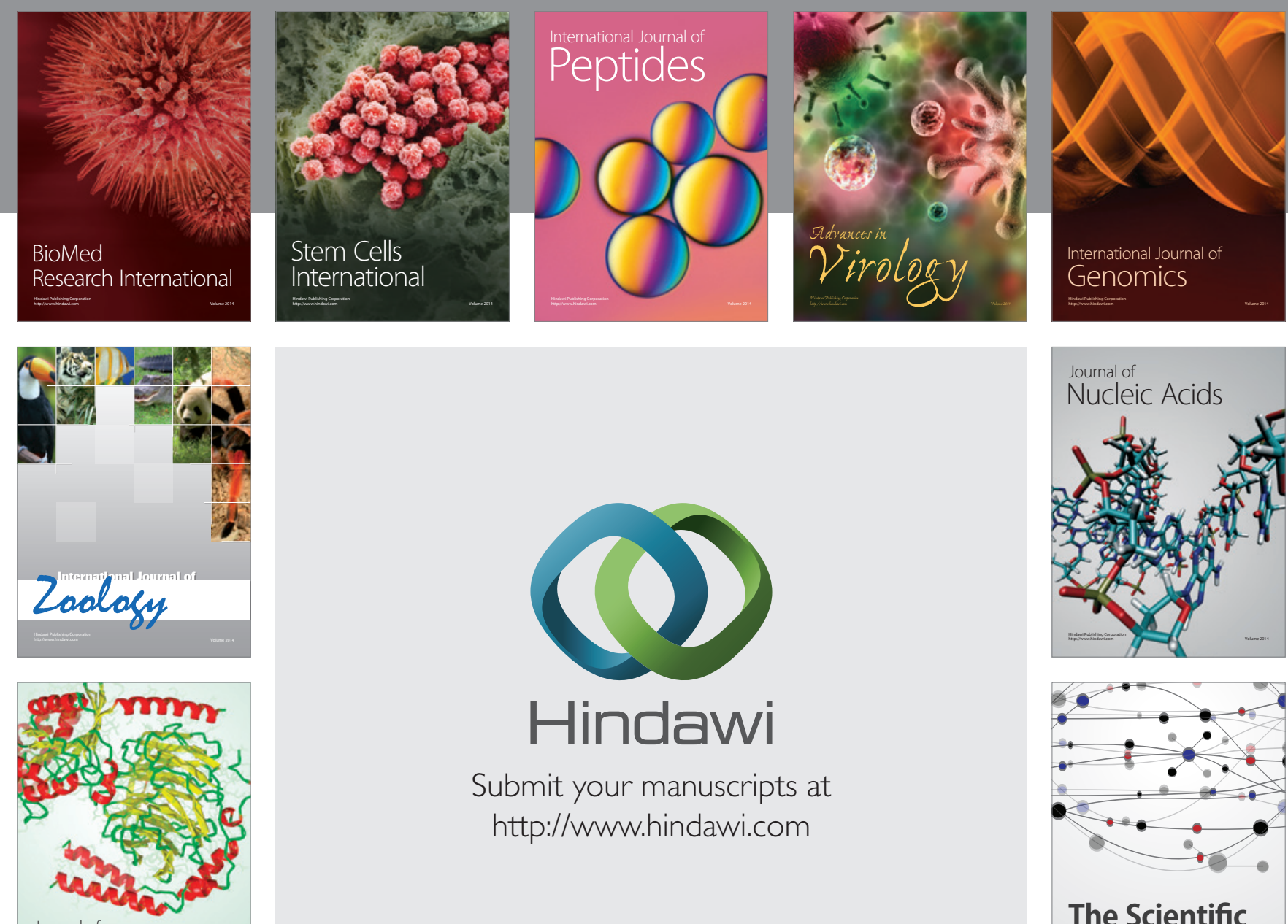

Submit your manuscripts at

http://www.hindawi.com

Journal of
Signal Transduction
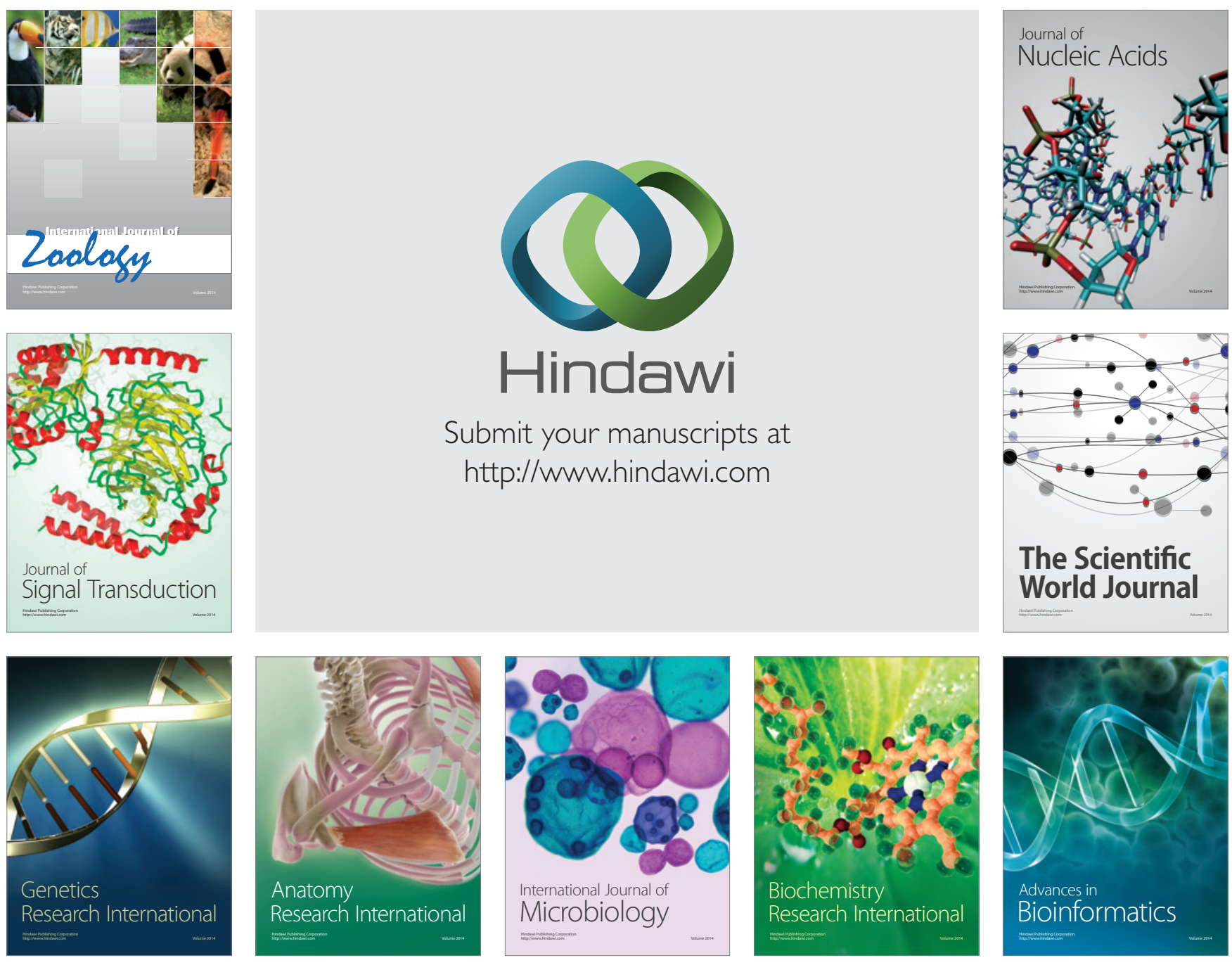

The Scientific World Journal
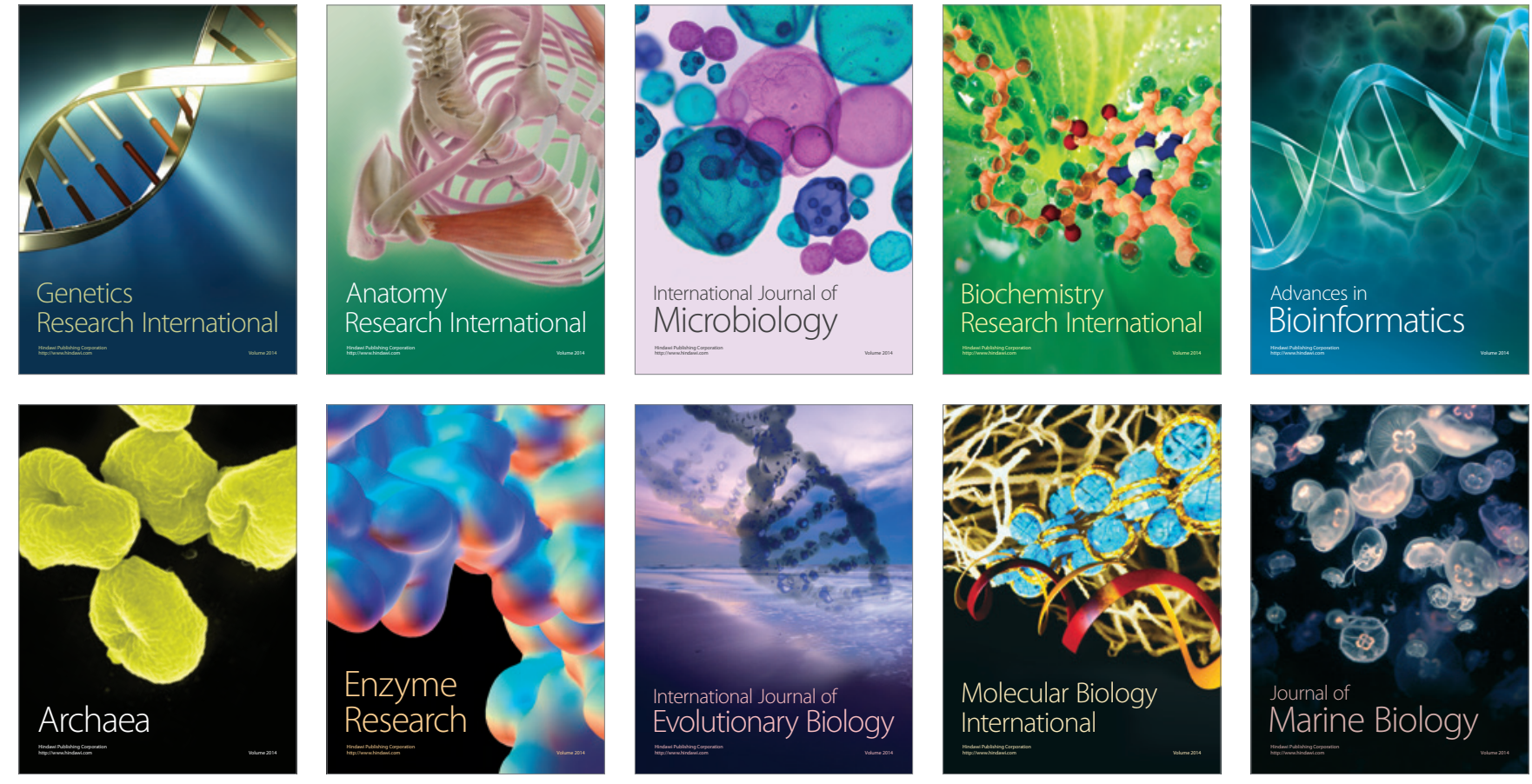